\title{
ROS1 Gene Alteration Positive
}

National Cancer Institute

\section{Source}

National Cancer Institute. ROS1 Gene Alteration Positive. NCI Thesaurus. Code C134454.

A finding indicating that mutation, overexpression or rearrangement of the ROS1 gene has been detected in a sample. 